IZA DP No. 8828

\title{
Age, Cohort and Co-Authorship
}

Daniel S. Hamermesh

February 2015 


\title{
Age, Cohort and Co-Authorship
}

\author{
Daniel S. Hamermesh \\ Royal Holloway University of London, \\ University of Texas at Austin, IZA and NBER
}

\section{Discussion Paper No. 8828 \\ February 2015}

\author{
IZA \\ P.O. Box 7240 \\ 53072 Bonn \\ Germany \\ Phone: +49-228-3894-0 \\ Fax: +49-228-3894-180 \\ E-mail: iza@iza.org
}

\begin{abstract}
Any opinions expressed here are those of the author(s) and not those of IZA. Research published in this series may include views on policy, but the institute itself takes no institutional policy positions. The IZA research network is committed to the IZA Guiding Principles of Research Integrity.

The Institute for the Study of Labor (IZA) in Bonn is a local and virtual international research center and a place of communication between science, politics and business. IZA is an independent nonprofit organization supported by Deutsche Post Foundation. The center is associated with the University of Bonn and offers a stimulating research environment through its international network, workshops and conferences, data service, project support, research visits and doctoral program. IZA engages in (i) original and internationally competitive research in all fields of labor economics, (ii) development of policy concepts, and (iii) dissemination of research results and concepts to the interested public.
\end{abstract}

IZA Discussion Papers often represent preliminary work and are circulated to encourage discussion. Citation of such a paper should account for its provisional character. A revised version may be available directly from the author. 
IZA Discussion Paper No. 8828

February 2015

\section{ABSTRACT}

\section{Age, Cohort and Co-Authorship*}

The previously documented trend toward more co- and multi-authored research in economics is partly (perhaps 20 percent) due to different research styles of scholars in different birth cohorts (of different ages). Most of the trend reflects profession-wide changes in research style. Older scholars show greater variation in their research styles than younger ones, who use similar numbers of co-authors in each published paper; but there are no differences across cohorts in scholars' willingness to work with different coauthors. There are only small gender differences in the impacts of age on numbers of coauthors, but substantial differences on choice of coauthors.

JEL Classification: A11, J01, B31

Keywords: $\quad$ sociology of economics, bibliometrics, rewards in economics

Corresponding author:

Daniel S. Hamermesh

Royal Holloway University of London

Department of Economics

214 Horton Building

Egham, Surrey TW20 0EX

United Kingdom

E-mail: Daniel.Hamermesh@rhul.ac.uk

\footnotetext{
* I am indebted to Victoria Baranov, Marika Cabral, Barry Chiswick, Ronald Ehrenberg, Lea Kosnik, David Laband, Andrew Seltzer, Stephen Trejo, Adrian Wood, Tom Wiseman, participants in seminars at several universities, and especially John McDowell for helpful comments, and to James Brand and Callum Porter-Harris for superb research assistance.
} 


\section{Background}

In medicine and the natural sciences it has long been de rigueur for scientific articles to list numerous coauthors (Zuckerman, 1977). In economics co- and multi-authorship are increasingly the norm, as shown through the 1970s by McDowell and Melvin (1983) and through the early 1990s by Hudson (1996) and Laband and Tollison (2000). Especially noteworthy is the acceleration of co-authorship in economics since then. Consider the evidence in Table 1 (reproduced from Hamermesh, 2013), showing patterns of co-authorship in the three leading general journals in economics-the American Economic Review, the Journal of Political Economy and the Quarterly Journal of Economics. In the 1960s a jointly-authored paper was a rarity; today in these leading outlets it is standard. Moreover, these summary statistics show that the distribution of the number of authors of a paper in these journals has shifted monotonically rightward, so that today having four or more authors on a paper in these top journals is quite common.

Along with this growth in the number of authors on published papers in economics has come a surprising shift in the age distribution of those authors. From the 1960s through the early 1990s top-flight publishing in economics appeared to be a young person’s "game.” As Table 2 shows, beginning in the 1990s there was a sharp increase in the fraction of articles that included older coauthors. While the nearly twenty percent of coauthors ages 51 and over is still below the fraction of academic economists in that age range (Hamermesh, 2013), the distribution of ages of those publishing in these journals is much closer to their representation in the relevant population today than it was in the last half of the twentieth century.

This striking change in the age patterns of publishing and the increasing presence of older authors makes a positive examination of the relationship between aging and co-authoring 
interesting. In this essay I therefore examine several sets of data that I have assembled on patterns of co-authoring to discover some new facts about the relationship between co-authoring and age among economists. I focus on the determinants of the trend in co-authorship in relation to age and on the interactions among co-authors-the differences in age among them and the persistence of co-authoring relationships as careers progress.

\section{Age, Cohort or Time?}

Is the growth of co-authorship in economics publishing specific to the times? Does it result from the predominance among those currently publishing of scholars who came of age in the 2000s? Or does it stem from the effect of aging on scholars' behavior? This last possibility seems unlikely from the cross-section evidence above, since regression estimates in Hamermesh (2013) showed that scholars ages 51+ are no more likely than much younger scholars to publish co-authored works in the very top journals in the field. But that comparison does not allow us to examine this possibility seriously. To distinguish cohort effects from time effects, we need to obtain longitudinal data describing individuals' careers from their beginning until, where possible, advanced age (as pointed out by Borjas, 1985, in the analogous case of the time paths of immigrants' earnings relative to natives').

To examine these issues I have collected the publication records of all the economists ages 80 or under who were alive on January 1, 2014, and who are or were either: 1) Fellows of the Society of Labor Economists (SOLE); and/or 2) Winners of the Institute for the Study of Labor (IZA) Prize in Labor Economics or its Young Labor Economist Award. This population of awardees - this sample of labor economists—consists of 83 scholars, of whom I excluded four because I could not obtain curricula vitae that were less than four years old. The remaining sample members were born between 1933 and 1980 . 
The analysis is based on a highly selected sample of 79 people from the population of all scholars who might be classified as labor economists. It includes three Nobel Prize winners, five Past Presidents of the American Economic Association or the Royal Economic Society, six winners of the John Bates Clark Medal or its European equivalent (the Yrjö Jahnsson Award) and thirty-seven who are also Fellows of the Econometric Society (and who include all members of the first three groups as subsets).

The data set contains information on 3,968 articles published in journals by these 79 people up through early 2014. In constructing the data set I included both refereed and nonrefereed publications, although the overwhelming majority of papers apparently consist of refereed papers. Notes, comments, Presidential/Nobel lectures, etc., are all included, so long as they were published in a journal outlet. For each paper we collected the names of all authors listed on the paper, right-truncating (in two cases) at seven authors. The 79 authors' names are listed in the Appendix.

Unlike the samples underlying Tables 1 and 2, which include all authors regardless of their distinction who published in the most prestigious outlets in the economics profession in several particular years, this sample contains all the journal publications by a distinguished sample of authors. Thus as a first check on this new sample I examine whether the pattern of increasing co-authorship over time that was shown in Table 1 also prevailed here. Data describing the numbers and frequency distributions of journal articles published by these scholars in each of the same six decades as in Table 1 are presented in the upper panel of Table 3.

These data show very similar patterns of co-authorship to those in Table 1 . The fraction of co-authored papers rose from around two-fifths in the 1960s and 1970s to five-sixths in the 
2010s. These fractions are slightly above those in the first column of Table 1, but the rise in coauthorship is of similar size. The differences in levels may arise from the nature of research in what is predominantly an empirical sub-specialty and from the broad range of quality of the journals in which these scholars' articles are published.

Even beyond matching the secular change in the pattern of co-authorship, these data replicate the increasing fraction of multi-authored (3+ authors) papers conditional on any coauthorship. While the incidence of co-authorship rose sharply after the 1970s, the incidence of multi-authorship increased monotonically across the decades in this sample, so that in the 2010s a majority of these authors' publications were part of at least three-author collaborations. Indeed, in the current decade over one-sixth of their publications contain four or more authors.

The criteria for inclusion in the sample are based partly on career distinction, so that unsurprisingly the mean age of the sample members in 2014 is quite high—58. As the lower half of Table 3 shows, however, the mean age when the articles in the sample were published was only 45. The fifty-eight year range in authors' ages at time of publication ensures that we have enough sampling variation to examine the relationship among the incidence of co-authorship, trends and aging. The average age when these authors obtained their Ph.D. degree was twentyeight, but here too there is substantial variation: The age ranges from 24 to $35 .{ }^{1}$

The average number of journal articles published up through early 2014 in this sample was 50. Of course, the more senior members of the sample had published more articles, but even within age groups there are large differences in rates of publishing activity. Thus the 39 authors ages 60+ in 2014 had published an average of 65 papers, with a range of 20 to 184 journal articles, while those under age 50 in 2014 (21 of the authors) had published an average of 19

\footnotetext{
${ }^{1}$ Three of the sample members (all English, and all currently over age 60) do not have a doctorate. To retain them in all the empirical work, I imputed their Ph.D. age as twenty-eight, the mean in the rest of the sample.
} 
papers, with a range of 3 to 101 . In short, there is substantial sampling variation among these authors, even within the same age cohort, and even at the same calendar time.

Having shown that co-authorship and multi-authorship have risen in this sample, as in articles published in the top journals, we can use these data covering entire careers to examine whether their incidence has risen with age over these authors' careers. As a first step consider the results in Figures 1a and 1b, showing the relationship between authorship and birth year. They make it completely clear that co- and multi-authorship are more prevalent among scholars in more recent birth cohorts. ${ }^{2}$

That there has been an increase over time in the fraction of co-authored and multiauthored articles is well-known and clear from both of the data sets used in this study. Is this a general trend? Is it due to the increased fraction of older authors among publishers (since, as Table 2 showed, there has been a sharp increase in the fraction of older economists among authors of articles in leading journals), and authors have tended to do more co-authoring as they have aged. Or is it a cohort effect, with authors in more recent cohorts being more likely to coauthor at the same age as authors from earlier cohorts?

Let $\mathrm{C}_{\mathrm{iat}}$ be an indicator of a publication having been co-authored, where $\mathrm{i}$ is a publication, $\mathrm{a}$ is an indicator for the author (from among the 79 in this sample), and t represents the year. (A similar equation could be written for the number of authors on a paper.) Let $\mathrm{AGE}_{\text {at }}$ be author a's age in year $t$, and BIRTHYEAR $\mathrm{a}_{\mathrm{a}}$ be author a's birth year. Then we can estimate any of the following three equations:

\footnotetext{
${ }^{2}$ Among those ages $60+$ in the sample the average fraction of sole-authored papers was 0.41 , while the average number of authors was 1.83. But the ranges were 0.12 to 0.83 , and 1.17 to 2.55 . Similar heterogeneity exists among authors in the later cohorts, although that is partly due to the much smaller samples of articles for which they have been responsible. This generates the heteroskedasticity shown in the figures.
} 
(1a) $\mathrm{C}_{\mathrm{iat}}=\alpha_{0}+\alpha_{1} \mathrm{t}+\alpha_{2} \mathrm{AGE}_{\mathrm{at}}+\varepsilon_{\mathrm{iat}} ;^{3}$

(1b) $C_{\text {iat }}=\beta_{0}+\beta_{1} \mathrm{t}+\beta_{2}$ BIRTHYEAR $_{\mathrm{a}}+\xi_{\text {iat }}$,

or

(1c) $\mathrm{C}_{\mathrm{iat}}=\gamma_{0}+\gamma_{1} \mathrm{BIRTHYEAR}_{\mathrm{a}}+\gamma_{2} \mathrm{AGE}_{\mathrm{at}}+v_{\text {iat }}$,

where the $\alpha, \beta$ and $\gamma$ are parameters, and the $\varepsilon, \xi$ and $v$ are random error terms. Because of the identity:

$$
\mathrm{t} \equiv \mathrm{AGE}_{\mathrm{at}}+\text { BIRTHYEAR }_{\mathrm{a}}
$$

we cannot identify time, age and cohort effects separately; but we can identify the parameters in any of the three pairs implied by the variables included in equations (1). Since the literature has stressed the secular rise in co-authorship, I estimate only (1a) and (1b), implicitly assuming that there is a trend effect and trying to examine how much of the effect that is measured when $\alpha_{2}$ or $\beta_{2}$ is set equal to 0 is due to differential behavior across cohorts or with age.

Before estimating (1a) and (1b), much of what might be inferred from the estimates of (1b) is discernable from the statistics in Table 4. The first three columns describe the publishing activities of the 34 authors in the earliest cohort (Ph.D. received before 1980) in each of three time periods 1962-79, 1980-1999 and 2000-14. Within this cohort the propensity to co-author increased over time, as did the propensity to be involved in multi-authorships. The same increase is visible in columns (4) and (5) for the 29 scholars in the 1980-99 Ph.D. cohort. Comparing columns (2) and (4), or columns (3) and (5), the table also shows that during the same time period scholars from the earliest cohort were less likely than scholars from the middle cohort to co-author or be one of multiple authors. The point is demonstrated even more strongly by adding the statistics in column (6) to this comparison: The 16 members of the most recent cohort (Ph.D.

${ }^{3}$ I also use "calendar age" rather than "Ph.D. age" because of the three previously mentioned imputations of the latter and because two percent of the articles in the sample were published when or before the degree was received. None of the results discussed here changes qualitatively if we make this substitution. 
received between 2000 and 2012) are even more likely than scholars in either of the two earlier cohorts to have published co-authored articles, and even more likely to have multiple authors listed on their papers, between 2000 and 2014.

The comparisons suggested by Table 4 are borne out by the results of probits and ordered probits describing the propensity for co- and multi-authorship that are presented in Table 5. Throughout I present the probit derivatives describing co-authorship and cluster standard errors on the authors. ${ }^{4}$ The equations also include indicators for the decade in which the article was published, thus expanding $\alpha_{1}$ and $\beta_{1}$ into vectors of parameters and taking into account what Table 3 suggested were discrete increases in the propensity for co- and multi-authorships in the 1980s, the 1990s and the 2010s. ${ }^{5}$ The estimates of (1a) indicate that in a given decade older economists were less likely to write co- or multi-authored articles, while the estimates of (1b) show that scholars in the earlier cohorts were also less likely than their younger colleagues to publish such work. ${ }^{6}$

Adding author fixed effects to the estimates in columns (1) and (4) and including a quadratic in age does not change these conclusions. Indeed, over a 47-year interval of a scholar's journal publications (the longest that is observed in these data-for two authors in the sample) the expected incidence of co-authorship would have risen by 25 percentage points. The quadratic

\footnotetext{
${ }^{4}$ If we do not cluster, the estimated standard errors in these equations are typically around 40 percent of those shown in the table. If we exclude the author who, with 184 articles, is a very extreme outlier (the second-most published author has 125 publications), the absolute values of the parameters shown here increase slightly.

${ }^{5}$ The coefficients on the decadal indicators mirror the differences in co-authorship rates by decade shown in Table 4 . The vector as a whole is statistically significant and remains so even if we add a time trend to the specification.

${ }^{6}$ Excluding the four percent of articles published when a scholar was over age 65 (and thus probably excluding disproportionately articles that were not refereed), the impact of age in the probit in (1a) falls to -0.0050 (s.e. = 0.0020). Going further and excluding the eleven percent of articles published after the authors were age 60 reduces the estimated impact to -0.0043 (s.e. $=0.0020$ ). Similar small decreases in the estimated impact of Birth Year occur in re-estimates of (1b) and in the impacts in the ordered probits on the number of authors. The changes in all cases are thus minor and do not alter the general conclusions.
} 
terms are important-the rate of increase of co-authorship slows with age, as does the rate of growth in the number of authors listed on these scholars' articles. But even with the deceleration in these phenomena as the scholars age, the incidence of co-authorship in the sample only stops increasing after age 62, while the estimated number of authors never decreases with age within the sample range of ages.

Assuming that there is some trend in co-authorship, the identity in (2) prevents us from extricating cohort from aging effects in this trend. We can, however, infer how much of the gross upward trends in co- and multi-authorship are due to aging and/or cohort effects in this sample by comparing the estimate of $\beta_{1}$ with and without $\beta_{2}$ constrained to equal zero. Concentrating on the propensity for co-authorship, and estimating (1b) with only a time trend, the estimated probit derivative $\beta_{1}=0.0102$. With $\beta_{2}$ unconstrained the estimate of $\beta_{1}$ falls to 0.0079 . A reasonable conclusion is that age/cohort effects account for perhaps around 20 percent of the gross trend increase in the propensity to co-author. ${ }^{7}$

While we cannot break the identity in (2), we can take advantage of the fact that authors in the same birth cohort (and thus of the same age in a year when they both published journal articles) earned their Ph.D. degrees in different years. The correlation between birth year and Ph.D. year is, of course, very high (+0.98), but it is not one. I thus re-estimate (1b), expanding the specification to include Ph.D. year. The results when both birth year and Ph.D. year are included in the specification are shown in columns (3) and (6) of Table 5. Not surprisingly, the coefficients nearly sum to the estimates of $\beta_{2}$ presented in columns (2) and (5), and their individual significance levels are substantially reduced from those of the earlier estimates. Nonetheless, they do suggest that, given the year when they published and the year when they

\footnotetext{
${ }^{7}$ The estimates of the coefficients in the ordered probits describing the number of authors show a qualitatively similar set of results. The analogous estimates of the ordered probit coefficients are 0.0372 and 0.0324 .
} 
were born, those scholars who received their Ph.D. degree later in life (who can be viewed as having entered the profession later in life) were more likely to publish co- and multi-authored papers. ${ }^{8}$ This finding suggests that the trends in co- and multi-authorship have something to do with the research styles that one learns from what the profession is doing during one's Ph.D. program or very early in one’s publishing career.

A number of other variables might be expected to alter the relationships described in (1). For example, respondents who have positions in the best economics departments might have more and better Ph.D. students with whom to coauthor. Adding an indicator for the top ten economics departments in North America and the top two in the United Kingdom, which describes almost half the 79 respondents, to the estimates in Table 5 of Equations (1a) and 1b) never changes the first significant digit of the estimate of the crucial parameter; and the indicator itself, although it enters positively, has t-statistics well below one. Another possibility is that coauthoring practices are different between North America and the rest of the world, and that this difference is correlated with age/cohort. Scholars at North American institutions, who account for five-sixths of the sample, are (nearly significantly) less likely to co-author, and have fewer co-authors when they do, than scholars of the same age at the same time on other continents. Nonetheless, the estimated effects of age or birth year hardly change in size or statistical significance from what is shown in Table 5.

Until fairly recently tabulations of citations only recorded the name of the first author of an article; and even now the custom in the text of a published paper is to list no more than two authors, relegating additional authors to inclusion in "et al." Not wishing to be known as "Al,", and in a discipline where alphabetical order is customary (see Engers et al, 1999), scholars with

\footnotetext{
${ }^{8}$ The results and comparisons are nearly identical if we exclude the three authors whose Ph.D. year was assigned and their 269 published articles from the sample.
} 
surnames late in the alphabet may strategically avoid or limit their co-authoring. To examine this possibility I created a variable ranging from 1 for "A" to 23 for "W" in this sample, indicating the numerical position of the first letter of the scholar's surname, and added it to the estimates of (1a) and (1b). Its inclusion changed the estimated impact of age (birth year) by less than two in the second significant digit, and its own coefficients were unexpectedly positive, although with tstatistics less than one.

Overall the results suggest that cohort effects are important in explaining the observed upward trends in co- and multi-authorship in economics. The dominant component of those trends, however, is general and cannot be attributed to differences in behavior among scholars of different cohorts, nor to changes in co- and multi-authorship patterns with age. While the causes of these (about which I speculated in Hamermesh, 2013, and which Jones, 2009, modeled) are unclear, they are not the result of inherent differences in people's behavior resulting from aging or from differences among people educated at different times.

\section{Prior Co-authoring and Productivity}

Does having relied more on co-authors in the past alter the relationship between age and publishing productivity? It is difficult to infer causation— to distinguish heterogeneity from state dependence in co-authoring — but we can infer whether those who are more prolific publishers with age have had more previous co-authors. Also, this examination has implications for people's responses to the incentives to publish.

In the sample of 79 labor economists I measure the years since the most recent prior publication for all but each author's first published article. Not surprisingly given the distinction of the scholars in this sample, 57 percent of papers appear in years when the author publishes two or more papers; and another 34 percent appear in print the year after another published 
paper. Nonetheless, six percent of the published papers in the sample appeared after a two-year hiatus, two percent after a three-year hiatus, and one percent after four years, so that there is scope for examining how the length of time between publications relates to the author's prior coauthoring practice. $^{9}$

Estimates of Poisson regressions describing the hiatus between publications are presented in Table 6, which gives results that are qualitatively the same as those of estimates of Poisson regressions describing the numbers of publications in a given year. ${ }^{10}$ In each equation I include the same vector of indicators of the decade of publication as was included in the estimates shown in Table 5. The results in the first column show that there is a negative, but statistically insignificant relationship between time since publication and the author's age. Most important, the estimates in the second and third columns show that having previously published more coauthored or multi-authored papers is associated with a shorter hiatus between publications. The estimates in both columns approach statistical significance. ${ }^{11}$

The positive effect of prior co- and multi-authorship on the frequency of publication might be related to heterogeneity in the sample. For example, it may be that authors from the earlier cohorts in the sample, since I selected them based on substantial lifetime achievement, might have published more frequently at the same age than authors from later cohorts. One way to examine this possibility is to include both age and patterns of prior co- and multi-authorship in the equations. Estimates of these expanded equations are shown in the fourth and fifth columns

\footnotetext{
${ }^{9}$ Only 0.4 percent of the articles appeared after a five-year or longer hiatus. None of the results discussed in this section is at all sensitive to the inclusion of these few observations in the estimation.

${ }^{10}$ The equations were all re-estimated using a negative binomial estimator. While the dependent variable is significantly over-dispersed, so that this estimator is more appropriate than the Poisson estimator, the coefficient estimates are hardly affected. I thus present the more easily interpreted Poisson estimates.

${ }^{11}$ If we exclude the six authors whose most recent publication appeared before 2010, which deletes 258 articles from the sample, the results shown in the table hardly change.
} 
of Table 6. They make it clear that this sort of heterogeneity does not matter: The parameter estimates change only slightly from those in columns (2) and (3), and their statistical significance increases.

The authors in this sample are heterogeneous along a variety of unknowable dimensions. To account for this fact I re-estimate the equations in columns (2) and (3) including fixed effects for each author, which generates only small changes in the parameter estimates. Overall, the results suggest that having had more co-authors is associated with more frequent subsequent publication. Indeed, given the estimates that are produced when author fixed-effects are included, one might even infer that this relationship is causal—that co-authoring makes one more productive (when one defines productivity as a count of the number of publications). For a given individual, having had more coauthors up to a particular age leads the scholar to publish more quickly subsequently.

\section{Age and the Choice of Coauthors}

The choice of coauthors reflects the outcome of a matching process. One chooses coauthors based on such factors as complementarities in production, but perhaps also on one's personal preferences-how comfortable one feels working with different individuals. While we cannot examine complementarities in production here, in this and the next section we examine how preferences for people "like oneself"-particularly age and gender—are exhibited. ${ }^{12}$

\section{A. The Relation Between Age and Coauthors' Ages}

The data underlying Tables 1 and 2 can provide an initial look at how the choice of coauthors differs by the age of authors. Consider the statistics in the first row of Table 7, showing the mean absolute age differences between coauthors of two-authored articles in these

\footnotetext{
${ }^{12}$ Freeman and Huang (2014) examine another demographic characteristic — ethnicity—in the process of matching of coauthors.
} 
journals by age of author, where each article is counted as one observation. ${ }^{13}$ Young authors (ages 35 and below) and mid-career authors (ages 36-50) have remarkably similar patterns in the ages of those with whom they publish: The average coauthor of scholars in these age groups is pretty much the scholar's contemporary. That is not true for the (relatively small and elite) group of older coauthors (those ages 51+). Their coauthors tend to be much different in age-averaging nearly 15 years different. Nearly all the older authors in the sample co-authored with people in the other two age groups, not with their contemporaries. Thus while we observe partnerships among contemporaries until the latter part of a career, partnerships late in a career are disproportionately with younger people. Their coauthors are not, however, likely to be their very recent Ph.D. students: With an average age of these older scholars of 58, a mean absolute difference of 15 years suggests that they are typically co-authoring with their mid-career colleagues.

Why might the difference in the age structure of co-authoring relationships change with age? One likely explanation is suggested by the relative, albeit decreasing rarity of older authors' appearances in this group of elite publishers. With the majority of older economists having ceased publishing, or even trying to publish, the set of potential coauthors with whom a productive older scholar can choose to work necessarily consists mostly of younger scholars. The results in Table 7 are explicable by propinquity of interest and energy. ${ }^{14}$

Some direct evidence on this explanation is obtainable by dividing the sample into articles published before and after 1990, taking advantage of the rise in the prevalence of older authors. The statistics are shown in the bottom rows of Table 7 . While the age differences

\footnotetext{
${ }^{13}$ There are too few multi-authored articles involving older authors to make any statistical analysis worthwhile.

${ }^{14}$ They seem consistent with the results of Fafchamps et al (2010) showing the role of nearness within a social network on the choice of coauthors.
} 
between coauthors ages 35 or less, or 36-50, did not change significantly over time, older coauthors worked with others who were significantly closer to their age in the latter period than before 1990. This change is consistent with the increasing availability of publishing older authors, providing their peers with an easier search for coauthors who were contemporaries.

\section{B. The Stability of Co-authoring Patterns over the Life Cycle}

A related issue is how scholars vary their co-authoring patterns with age, and the extent to which the choice of individuals with whom to coauthor persists over time. To examine the first question I use the data on the 79 distinguished labor economists that underlay the analyses in Sections II and III. For each publication after an author's first I form the coefficient of variation of the number of authors up to and including that publication. To the extent that the number of authors exhibits some randomness across publications, the coefficient of variation will decrease over an author's career (as the author ages). Thus in the analysis here I exclude the first ten (alternatively the first forty) publications by each author. The mean coefficient of variation of the number of authors on their $41^{\text {st }}$ and later articles is 0.40 .

Table 8 shows estimates of regression equations describing the coefficient of variation of the number of coauthors on all articles beyond the tenth (fortieth). To account for possible changes in co-authoring behavior beyond those shown in Section II, the estimates hold constant the indicators of the decade when the article was published. The results are remarkably insensitive to the choice of sample: Those in later birth cohorts (younger authors) are significantly less likely to vary the number of scholars with whom they coauthor than are scholars who are born earlier (older authors). ${ }^{15}$ These two outcomes are quite strongly

\footnotetext{
${ }^{15}$ This result is not due to the fact that older authors who publish in a given year have published more papers up to that date: In an expanded specification that includes the number of articles each author has produced to date the estimated absolute impact of birth year on the coefficient of variation of the number of authors declines but it remains significantly negative.
} 
associated: Moving from birth year 1934 to 1967, the extremes in the sample of articles that are at least the $41^{\text {st }}$ in an author's career, decreases the coefficient of variation by 1.8 standard deviations.

The co-authoring behavior of scholars from earlier cohorts is less stable than that of scholars born later, independent of any confounding factors such as the dates when they published. The difference is not due to greater experience (since I held the number of their publications constant), but perhaps arises from their learned ability to pick out co-authors when that is appropriate and to author alone when it is not, or perhaps to differences in preferences across birth cohorts.

\section{Age and the Identity of Coauthors}

While authors from older cohorts exhibit less stable co-authoring behavior, that fact says nothing about the identity of the scholars with whom they co-author. Their behavior could be less stable, but they could be choosing the same individual or set of scholars when they coauthor. To examine their stability defined in terms of their choices of individuals rather than their number, I calculate for each article the cumulative number of different coauthors with whom the scholar has published and the cumulative total number of coauthors, and then define their ratio as the "novelty index" of co-authorship. The novelty index ranges from 0.21 to 1.00 over all the 2701 co-authored articles in the sample. Figure 2 presents a scatter of this index and birth year for the most recent publication by each of the 79 authors. There is absolutely no relationship between the two measures: The most recent article published by someone in a more recent cohort is no less likely to reflect repeated matches with particular coauthors than is one by a scholar born earlier. 
Estimates of the relationship between the novelty index and the author's birth year are presented in column (1) of Table 9 using all 2701 observations; but unlike in the equation fitted to the scatter in Figure 2, here I include a vector of indicators of the decade when the article was published. The results demonstrate that, once we use the cumulative history of all the coauthored articles in the sample, we observe that those in more recent cohorts are more likely to exhibit novelty in their choice of coauthors. The difficulty with this conclusion is that scholars from more recent cohorts (younger authors) have typically written fewer articles, and even fewer co-authored articles, than their senior colleagues. They can be viewed as being engaged in the early stages of a search process for coauthors. One’s first co-authored paper is ipso facto written with new coauthor(s), and to the extent that there is some randomness in the choice of coauthors, the next few are more likely to be written with new faces than are subsequent ones. Indeed, the estimates in column (2) of Table 9 suggest exactly this - each additional co-authored article reduces the share of an author's new coauthors. Accounting for this fact in column (3), we see that there is absolutely no relationship between birth year (age) and the novelty of coauthors once the authors' differential writing experience is accounted for (holding constant the date when the paper was published).

As an additional step in examining this issue we can consider whether co-authoring partnerships are stable over a career. Restricting the sample to the 39 authors ages 60+ in 2014 (to allow sufficient time to observe repeated matches), only 36 of the 274 unique co-authorship matches into which these authors entered before age 41 were repeated after age $50 .{ }^{16}$ Matching with co-authors does not appear very persistent in this sample—most economists do not "mate"

\footnotetext{
${ }^{16}$ As an aside on this comparison, of the 2237 unique coauthor matches in the sample, only 10 percent represent matches that persisted for more than five years (i.e., the authors have published papers with each other that are at least five years apart). Only one percent of coauthor pairs published together over a 20+ year period, with the maximum interval in the sample being 28 years.
} 
for (their professional) life. Rather, co-authoring in this elite group seems driven by the desire to find the best person or people to work with on specific research questions.

\section{Aging Female Coauthors}

Are women different from men in their co-authoring behavior, in terms of the likelihood of ca-authoring as they age and in the relationship between age and the number of coauthors? Previous evidence (McDowell et al, 2006) suggests that gender differences in the propensity to coauthor in economics do exist, and Abrevaya and Hamermesh (2012) demonstrate the existence of gender-matching among coauthors. Re-estimates of the models in Section II, however, suggest no difference between men and women in the relationship among age, cohort and time trends in this elite sample (although the paucity of women, 12 of 79 authors, and of their articles, 412 of 3968, sharply reduces the precision of the estimated impact of age for women compared to that for men). We cannot reject the hypothesis that pooled results presented in Table 5 describe men's and women's behavior equally well. Female authors are no different from their male counterparts of the same age (cohort) in reflecting the trend toward co-authorship that has characterized published research in economics.

Although the number of authors by age and time period appears independent of gender, perhaps female scholars, whose search for co-authoring partners may differ from that of male scholars, choose their coauthors differently as they age. One possibility is that limitations on search may lead them to "settle down" more than men once they have found coauthors to work with. To examine this possibility, the left-hand side of Table 10 presents descriptive statistics on co-authoring behavior by gender, including the number of coauthors and the number of different coauthors. Given the increase in women's participation in the profession, it is unsurprising that the women in the sample are younger, have published fewer papers and have fewer coauthors. 
What is remarkable is that the novelty index is nearly identical for men and women (0.55 and 0.56). ${ }^{17}$ Despite the differences in age of men and women in the sample, novelty in co-authorship is the same for both.

Generalizing from these results may be difficult because five of the twelve women in the sample repeatedly co-author with their spouse/partner, who in some cases is also in the sample. Less important, given the large number of men in the sample, five of the men repeatedly coauthor with their spouse/partner. To remove the possible "contamination" of inferences about the search for co-authoring partners by the (previously successful) search for life partners, I delete these ten individuals from the sample. The right-hand side of Table 10 presents the descriptive statistics for this reduced sample. The remaining women are younger than those who have been deleted (and have published less and have fewer coauthors); but the results on search for coauthors remain essentially unchanged, with the novelty index rising very slightly to 0.56 and 0.58 for men and women respectively.

The sample of articles published each decade in the top three general journals that underlay Tables 1 and 2 allows examining whether the general result in Section IV.A., that people choose coauthors of similar ages, differs by gender among authors age 50 or less. (None of the co-authored articles in that sample includes women over age 50, so that I cannot examine this issue for scholars over age 50.) The scarcity of even middle-aged female authors might suggest that they are forced to seek out much younger scholars if they wish to collaborate. Comparing authors who are age 35 or less to those who are age 36-50, the average age difference between male authors in the younger group is six years, while that between female authors is five years. The difference between male authors in the older age group is also six years, while female

\footnotetext{
${ }^{17}$ Regressions that hold constant the author's birth year, the article number and the date of publication of the article suggest that the absence of gender differences is not due to correlations with other covariates.
} 
authors age 36-50 write with people who differ in age from them by seven years. The doubledifference of two years in age of coauthors by gender is consistent with the need for (the relatively few) middle-aged female coauthors to spread their nets more widely as they age (although the relatively small number of female authors means that the double-difference is not statistically significant).

\section{Older and Younger Coauthors}

Do authors in different cohorts differ in productivity? The difficulty in answering that question is, of course, how one defines productivity. Here I answer this question only very partially, defining productivity as the number of full-time-equivalent journal articles written over a career. Implicitly I am dividing a paper's quality by $\mathrm{N}$, where $\mathrm{N}$ is the number of co-authors listed on the paper. I am also ignoring differences in quality, as measured by scholarly impact, that may be related to the joint variation of number of authors and cohort.

Taking this admittedly partial approach, we can at least examine how trends in coauthorship and differences in behavior by cohort affect inter-cohort comparisons of output (defined here only by quantity). To minimize differences in input quality, I use the sample of labor economists, and I restrict the sample still further to those members who are also Fellows of the Econometric Society and are thus the more successful scholars in this already highly selective sample.

The first two columns of Table 11 describe the publishing behavior before age 60 of Fellows in the birth cohorts after 1954 and before 1955. The variables described in the first two rows are obvious and show that the Fellows in the earlier cohort were elected at later ages on average. The number of articles written is almost identical across the two cohorts, but members of the more recent cohort have had more coauthors. The table then shows the ratio of full-time- 
equivalent (FTE) to total articles, calculated as the number of articles divided by the number of authors. Unsurprisingly given the results in Section II, this ratio is higher among members of the earlier cohort.

If the overall quality of research completed by members of these cohorts of very successful economists has not changed across cohorts (or at least not changed relative to research in the profession as a whole); and if one viewed the appropriate divisor by which to apportion credit for co-authored articles as $\mathrm{D}^{*}$ early when the earlier cohort was being considered for promotion/appointment, then the appropriate divisor for assigning credit among authors in more recent cohorts should be higher. With the same inherent quality, today's top scholars are publishing more papers per year than their top predecessors. Indeed, given the change in FTE/article shown in Table 11, one might conjecture that the appropriate divisor today is $\mathrm{D}^{*}{ }_{\text {recent }}$ $=1.33 \cdot \mathrm{D}^{*}$ early (i.e., $1.33=0.651 / 0.490$ ), thus accounting for the increasing propensity to coauthor over time. Whatever divisor one uses to assign credit at a point in time, this evidence suggests that one should use a larger divisor when comparing publication lists of scholars in more recent cohorts to those of scholars in older cohorts.

One might argue, based on differences in the first two rows of the left-hand columns in Table 11, that the authors in these two birth cohorts in this sub-sample are not comparable in terms of ability. To account for this possibility, I further restrict the sample to authors who were elected Fellows before age 50 and consider only publications before that age in both cohorts. ${ }^{18}$ The right-hand columns of Table 11 show the results for this even more restricted sub-sample. Members of these cohorts look remarkably similar in terms of the ages at which they were elected Fellows and the ages at which their average publication in print before age 50 was

\footnotetext{
${ }^{18}$ This restriction retains all the sample members who had achieved the additional distinctions mentioned in Section
} II. 
produced. Scholars in the more recent cohort published many more articles before this age, but they also worked with more coauthors. The FTE/article is much lower than that of the earlier cohort. Indeed, the numbers of FTE articles are almost identical for the two cohorts, 15.5 in the more recent cohort and 15.4 in the earlier cohort. The ratios hardly change from their values in the first two columns, suggesting that this further attempt to compare scholars of identical ability does not alter the conclusion that today's divisor should be well above what it had been..

\section{Implications and Summing Up}

The economics profession is aging. Using a large data set on lifetimes of publishing of a number of distinguished scholars, I have shown that this fact and differences in research habits across cohorts of scholars can explain only a small part of the simultaneous trend toward more co- and multi-authorships of scholarly articles in the field. While scholars' choices of research methods as they age appear to become more eclectic - they exhibit more variation in the number, if any, of coauthors - they are no more likely than their younger peers to choose to work with different sets of co-authors on successive publications.

Working with other scholars is basically a search process-involving both personal preferences and potential production complementarities. Nearly all the findings here are consistent with the implications of search theory. In particular, the increasing positive assortative matching of older coauthors over time, and the changing interaction of gender and age in coauthoring behavior, are explicable by the increasing percentages of older scholars and women among those publishing articles in economics.

All the empirical results in this study are based on elite samples, in one case of individual scholars who have achieved substantial distinction over their careers, in the other of articles published in the three leading general journals in the field. Obviously these are not random 
samples of journals or scholars; but these authors and published works are the leaders in the field, reflecting the research that generally receives the most attention from other scholars. Moreover, given the general decline in publication rates with age, which is especially sharp for those who are relatively less productive early in their careers (Oster and Hamermesh, 1998), if anything our results understate the effect of age on co-authorship and productivity. For those reasons, while not necessarily representative of the co-authoring behavior of all economists or of the content of all economic research, the results here indicate what is occurring at what is arguably the forefront of the economics literature.

As today's earlier birth cohorts are replaced by scholars from later cohorts who have developed somewhat different research habits, the results suggest that the trend toward increasing co- and multi-authorship will continue. To the extent that these collaborations enhance scholarly productivity, the disappearance of more senior scholars whose habits do not lead them toward collaboration can be viewed as beneficial. The central question for considering the structure of scholarly inquiry, however, is whether the marginal scholarly collaboration is truly productivity enhancing, or, if instead of collaborating, the same scholars would contribute more by working on their own. 


\section{REFERENCES}

Jason Abrevaya and Daniel Hamermesh, "Charity and Favoritism in the Field: Are Female Economists Nicer (To Each Other)?” Review of Economics and Statistics, 94 (Feb. 2012): 202-07.

George Borjas, "Assimilation, Changes in Cohort Quality, and the Earnings of Immigrants," Journal of Labor Economics, 3 (Oct. 1985): 463-89.

Maxim Engers, Joshua Gans and Simon Grant, "First-Author Conditions," Journal of Political Economy, 107 (Aug. 1999): 859-83.

Marcel Fafchamps, Marco van der Leij and Sanjeev Goyal, "Matching and Network Effects," Journal of the European Economic Association, 8 (March 2010): 203-31.

Richard Freeman and Wei Huang, "Collaborating with People Like Me: Ethnic Co-Authorship Within the U.S.,” NBER Working Paper No. 19905, 2014.

Daniel Hamermesh, “Six Decades of Top Economics Publishing: Who and How?” Journal of Economic Literature, 51 (March 2013): 162-72.

John Hudson, "Trends in Multi-Authored Papers in Economics," Journal of Economic Perspectives, 10 (Summer 1996): 153-8.

Benjamin Jones, "The Burden of Knowledge and the 'Death of the Renaissance Man': Is Innovation Getting Harder?” Review of Economic Studies, 76 (Jan. 2009): 283-317

Pantelis Kalaitzidakis, Theofanis Mamuneas and Thanasis Stengos, "An Updated Ranking of Academic Journals in Economics,” Canadian Journal of Economics, 44 (Nov. 2011): 1525-38.

David Laband and Robert Tollison, "Intellectual Collaboration," Journal of Political Economy, 108 (June 2000): 632-62

John McDowell and Michael Melvin, "The Determinants of Co-authorship: An Analysis of the Economics Literature,” Review of Economics and Statistics, 65 (Feb. 1983): 155-60.

-----------------, Larry Singell and Mark Stater, "Two to Tango? Gender Differences in the Decisions to Publish and Coauthor,” Economic Inquiry, 44 (Jan. 2006): 153-68.

Sharon Oster and Daniel Hamermesh, "Aging and Productivity among Economists," Review of Economics and Statistics, 80 (Feb. 1998): 154-6.

Harriet Zuckerman, Scientific Elite: Nobel Laureates in the United States. New York: Free Press, 1977. 
Table 1. Distribution of Full-Length Refereed Articles by Co-authorship Status, AER, JPE and QJE, 1963-2011*

\begin{tabular}{lccccc} 
Year & $\begin{array}{c}\text { Number of } \\
\text { Articles }\end{array}$ & \multicolumn{4}{c}{ Distribution of Number of Authors } \\
& & $\operatorname{Pr}\{\mathbf{2}+\}$ & $\operatorname{Pr}\{\mathbf{3} \mid \mathbf{2}+\}$ & $\operatorname{Pr}\{\mathbf{4} \mid \mathbf{3}+\}$ & $\operatorname{Pr}\{\mathbf{5} \mid \mathbf{4}+\}$ \\
1963 & 86 & 0.163 & 0.000 & 0.000 & 0.000 \\
1973 & 119 & 0.286 & 0.029 & 0.000 & 0.000 \\
1983 & 125 & 0.456 & 0.140 & 0.000 & 0.000 \\
1993 & 136 & 0.551 & 0.280 & 0.095 & 0.000 \\
2003 & 135 & 0.741 & 0.280 & 0.214 & 0.000 \\
2011 & 147 & 0.796 & 0.385 & 0.222 & 0.200
\end{tabular}

*Includes all full-length original articles, except Nobel and Presidential addresses. Calculated from Table 2 of Hamermesh (2013). 
Table 2. Percent Distributions of Age of Authors, Top Three General Economics Journals, 1963-2011*

\section{Age Distribution of Authors}

$\begin{array}{llll}\text { Year } & \leq 35 & \mathbf{3 6 - 5 0} & \mathbf{5 1 +} \\ \mathbf{1 9 6 3} & 50.5 & 45.3 & 4.2 \\ \mathbf{1 9 7 3} & 61.5 & 32.6 & 5.9 \\ \mathbf{1 9 8 3} & 48.5 & 47.2 & 4.3 \\ \mathbf{1 9 9 3} & 49.8 & 43.1 & 7.1 \\ \mathbf{2 0 0 3} & 36.8 & 50.4 & 12.8 \\ \mathbf{2 0 1 1} & 33.0 & 48.1 & 18.9\end{array}$

*Includes all full-length original articles, except Nobel and Presidential addresses. Age could not be found for 3 authors in 1963, 1 author in 1973. The distributions are weighted by the inverse of the number of authors in the publication. Calculated from Table 1 of Hamermesh (2013). 
Table 3. Distribution of Journal Articles by Co-authorship Status, 79 Labor Economists, 1964-2014, and Descriptive Statistics-Means, Standard Deviations and Ranges

\begin{tabular}{|c|c|c|c|c|c|}
\hline \multirow[b]{2}{*}{ Year } & \multirow{2}{*}{$\begin{array}{l}\text { Number of } \\
\text { Articles }\end{array}$} & \multicolumn{4}{|c|}{ Distribution of Number of Authors } \\
\hline & & $\operatorname{Pr}\{2+\}$ & $\operatorname{Pr}\{3+\mid 2+\}$ & $\operatorname{Pr}\{4+\mid 3+\}$ & $\operatorname{Pr}\{5+\mid 4+\}$ \\
\hline $1960 s$ & 33 & 0.424 & 0.000 & 0.000 & 0.000 \\
\hline $1970 \mathrm{~s}$ & 338 & 0.328 & 0.129 & 0.067 & 0.000 \\
\hline $1980 \mathrm{~s}$ & 741 & 0.587 & 0.195 & 0.165 & 0.357 \\
\hline 1990s & 1081 & 0.717 & 0.289 & 0.156 & 0.143 \\
\hline $2000 s$ & 1273 & 0.739 & 0.451 & 0.267 & 0.265 \\
\hline $2010 s$ & 502 & 0.833 & 0.660 & 0.308 & 0.412 \\
\hline
\end{tabular}

Birth Year Ph.D. Year Age When Published Number of Articles Age at Ph.D.

$\begin{array}{ccccc}1956 & 1984 & 45.2 & 50.3 & 27.9 \\ (12.9) & (13.8) & (10.9) & (35.7) & (2.2) \\ {[1933,1980]} & {[1962,2012]} & {[21,79]} & {[3,184]} & {[24,35]}\end{array}$


Table 4. Descriptive Statistics of Articles, 79 Labor Economists, 3968 Articles, by Date Published and Author's Ph.D. Cohort

\begin{tabular}{llllll}
\multicolumn{5}{c}{$\begin{array}{c}\text { Author Ph.D. Year } \\
\text { Year Published }\end{array}$} \\
$1962-79$ & $1962-79$ & $1962-79$ & $1980-99$ & $1980-99$ & $2000-14$ \\
$1962-79$ & $1980-99$ & $2000-14$ & $1980-99$ & $2000-14$ & $2000-14$
\end{tabular}

\section{Authors}

\begin{tabular}{|c|c|c|c|c|c|c|}
\hline 1 & 62.2 & 39.6 & 34.4 & 22.9 & 16.2 & 15.1 \\
\hline 2 & 33.8 & 46.3 & 34.9 & 55.2 & 39.8 & 33.6 \\
\hline 3 & 3.7 & 12.0 & 21.6 & 18.3 & 31.8 & 37.1 \\
\hline 4 & 0.3 & 1.5 & 6.6 & 3.2 & 7.9 & 9.3 \\
\hline $5+$ & 0 & 0.6 & 2.5 & 0.5 & 4.3 & 4.9 \\
\hline N Articles & 370 & 1168 & 717 & 652 & 853 & 205 \\
\hline N Authors & 34 & 34 & 34 & 29 & 29 & 16 \\
\hline
\end{tabular}


Table 5. Estimates of the Determinants of the Number of Authors of Journal Articles, 79 Labor Economists, 3968 Articles, 1964-2014*

\section{Co-authored:}

Probit Derivatives

Equation: (1a) (1b)

Ind. Var.:
No. of Authors

Ordered Probit Coefficients

(1a) (1b)
Age
$-0.0051$
$------$
$(0.0045)$
Birth Year
$\begin{array}{cc}0.0062 & -0.0322\end{array}$
$0.0128-0.0580$
(0.0047) (0.0262)
Ph.D. Year
0.0375
(0.0103)
0.0684
(0.0250)
$\begin{array}{llll}\text { Pseudo-R }^{2} & 0.059 & 0.062 & 0.076\end{array}$
$0.053 \quad 0.055$
0.060

*All equations include a vector of indicators of the decade in which the article was published, with the 1960s as the excluded decade. Standard errors are clustered on the authors. 
Table 6. Poisson Estimates of the Determinants of Elapsed Time Between Publications, 1966-2014 ( $\mathbf{N}=3889) *$

Ind. Var.

$\begin{array}{llllll}\text { Age } & -0.0072 & ------- & ------- & -0.0099 & -0.0100 \\ & (0.0066) & & & (0.0068) & (0.0070) \\ \text { Prior Average } & -------- & -0.3670 & ------ & -0.4494 & ------- \\ \text { Co-Authored } & & (0.2161) & & (0.2210) & \\ \text { Prior Average } & -------- & ------- & -0.1745 & ------- & -0.2344 \\ \text { No. of Authors } & & & (0.1287) & & (0.1297) \\ & & & & & \\ \text { Pseudo-R } & & & & & \\ & 0.0044 & 0.0052 & 0.0045 & 0.0071 & 0.0064\end{array}$

*All equations include a vector of indicators of the decade in which the article was published, with the 1960s as the excluded decade. Standard errors are clustered on the authors. 
Table 7. Absolute Average Age Difference Between Authors of Two-Authored Articles, Top Three General Economics Journals, 1963-2011, Means, Standard Deviations and Number of Articles*

\section{Age of Coauthor}

Period: $\quad \leq 35 \quad 36-50 \quad 51+$

$\begin{array}{cccc}\text { All 6 years } & 6.1 & 6.1 & 14.6 \\ & (0.69) & (0.45) & (1.42) \\ & {[119]} & {[139]} & {[35]}\end{array}$

Subperiods:

1963, 1973, 1983

$\begin{array}{ccc}5.6 & 5.8 & 20.4 \\ (8.66) & (4.20) & (5.81) \\ {[45]} & {[46]} & {[5]}\end{array}$

1993, 2003, 2011

$\begin{array}{ccc}6.4 & 6.3 & 13.6 \\ (5.29) & (5.85) & (8.45) \\ {[74]} & {[93]} & 30]\end{array}$

*Includes all full-length original articles, except Nobel and Presidential addresses. Age could not be found for three authors in 1963, one author in 1973. 
Table 8. Regression Estimates of Relation of Birth Cohort to Lifetime Variation in Coauthoring Patterns (Dep. Var. is the Coefficient of Variation)*

Articles No.: 11+ 41+
All Years $>=2000$
All Years $>=2000$

Ind. Var.:

Birth Year

$-0.0035 \quad-0.0033$

(0.0009) (0.0009)

$-0.0033 \quad-0.0029$

(0.0014) (0.0013)

N Articles

3202

1604

1507

1081

N Authors

70

69

43

42

Adjusted $\mathrm{R}^{2}$

0.158

0.198

0.152

0.156

*The equations in columns (1) and (3) include a vector of indicators of the decade in which the article was published, with the 1960s and 1970s as the excluded decades. The equations in columns (2) and (4) include an indicator for the 2010s. Standard errors are clustered on the authors. 


\section{Table 9. Determinants of the Novelty Index of Coauthors (2701 Co-authored Articles)*}

Ind. Var.:

Birth Year

$$
0.0031
$$

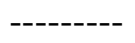

$-0.0008$

$(0.0015)$

$(0.0014)$

Article Number

$\begin{array}{lll}------- & -0.0019 & -0.0020 \\ & (0.0005) & (0.0005)\end{array}$

Adjusted $\mathrm{R}^{2}$

0.234

0.295

0.296

*All specifications include a vector of indicators of the decade when the article was published, with the 1960s as the excluded decade. Standard errors are clustered on the authors. 
Table 10. Coauthor Search and Gender, Descriptive Statistics (Means and Standard Deviations)

\begin{tabular}{|c|c|c|c|c|}
\hline \multicolumn{3}{|c|}{ All } & \multicolumn{2}{|c|}{ Non-Partnered } \\
\hline & Males & Females & Males & Females \\
\hline Birth Year & $\begin{array}{c}1955 \\
(13.19)\end{array}$ & $\begin{array}{c}1960 \\
(10.56)\end{array}$ & $\begin{array}{l}1955 \\
(13.48)\end{array}$ & $\begin{array}{c}1964 \\
(9.48)\end{array}$ \\
\hline $\begin{array}{l}\text { N Articles } \\
\text { Total }\end{array}$ & $\begin{array}{r}53.13 \\
(37.16)\end{array}$ & $\begin{array}{c}34.33 \\
(20.28)\end{array}$ & $\begin{array}{c}52.98 \\
(37.94)\end{array}$ & $\begin{array}{c}25.43 \\
(11.67)\end{array}$ \\
\hline N Coauthors & $\begin{array}{c}54.34 \\
(43.98)\end{array}$ & $\begin{array}{c}37.17 \\
(26.38)\end{array}$ & $\begin{array}{c}54.05 \\
(44.68)\end{array}$ & $\begin{array}{c}27.29 \\
(16.49)\end{array}$ \\
\hline $\begin{array}{r}\text { N Different } \\
\text { Coauthors }\end{array}$ & $\begin{array}{c}29.69 \\
(21.56)\end{array}$ & $\begin{array}{c}20.92 \\
(17.96)\end{array}$ & $\begin{array}{c}30.02 \\
(21.80)\end{array}$ & $\begin{array}{l}15.71 \\
(8.42)\end{array}$ \\
\hline N Authors & 67 & 12 & 62 & 7 \\
\hline $\begin{array}{c}\text { N Coauthored } \\
\text { Articles }\end{array}$ & 2399 & 302 & 2208 & 125 \\
\hline
\end{tabular}


Table 11. Publication Counts and "Full-Time" Equivalent Publications, Econometric Society Fellows-Means, Standard Deviations and Ranges

\author{
Publications before Age: \\ 60 \\ 50
}

\begin{tabular}{lcccc}
\multicolumn{1}{c}{ Sample: } & \multicolumn{2}{c}{ All Fellows } & \multicolumn{2}{c}{ Became Fellow before Age 50 } \\
\multicolumn{1}{c}{ Birth Year: } & $>\mathbf{1 9 5 4}$ & $<\mathbf{1 9 5 5}$ & $>\mathbf{1 9 6 4}$ & $<\mathbf{1 9 6 5}$ \\
Age When & 39.50 & 44.78 & 40.33 & 40.33 \\
Elected & $(5.53)$ & $(7.49)$ & $(5.01)$ & $(5.65)$ \\
& {$[33,53]$} & {$[33,60]$} & {$[33,47]$} & {$[30,49]$} \\
& & & & \\
Age When & 40.27 & 44.15 & 37.53 & 38.92 \\
Published & $(7.51)$ & $(8.94)$ & $(5.71)$ & $(6.29)$ \\
& {$[21,57]$} & {$[23,59]$} & {$[26,49]$} & {$[21,49]$} \\
Average Article & 34.02 & 35.67 & 33.03 & 26.00 \\
No. & $(23.39)$ & $(25.77)$ & $(26.70)$ & $(17.40)$ \\
FTE/Article & 0.490 & 0.651 & 0.487 & 0.628 \\
& $(0.106)$ & $(0.136)$ & $(0.114)$ & $(0.157)$ \\
N Authors & 14 & 23 & & \\
& & & & \\
N Articles & 780 & 1323 & 264 & 1050
\end{tabular}




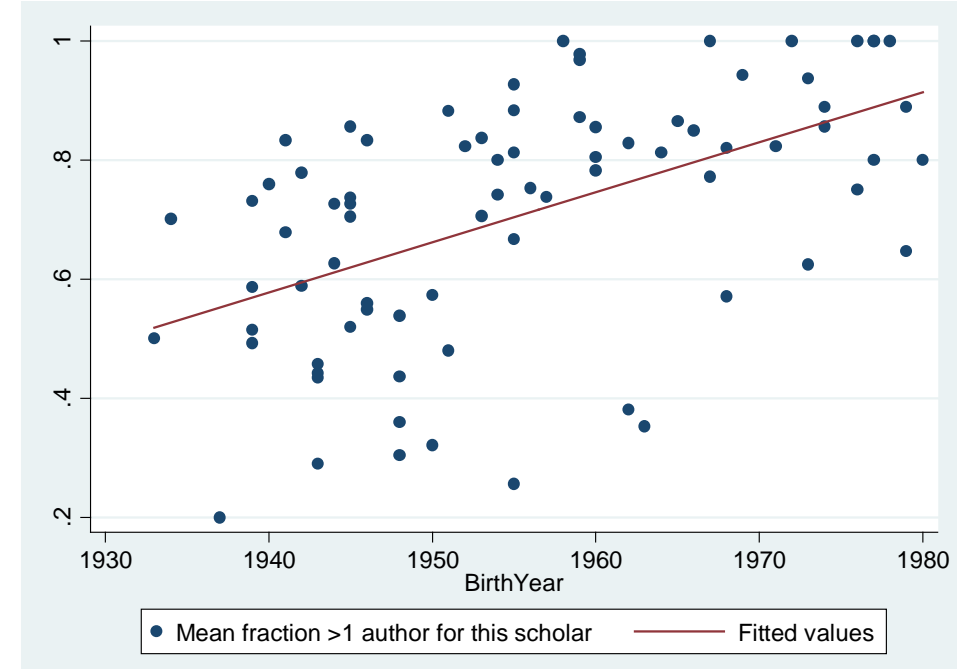

CoAuthor $=-15.74+0.0084$ BirthYear, Adj. $\mathrm{R}^{2}=0.269$ (0.0015)

Figure 1a. Relation between Birth Year and Co-authorship, $\mathbf{N}=79$

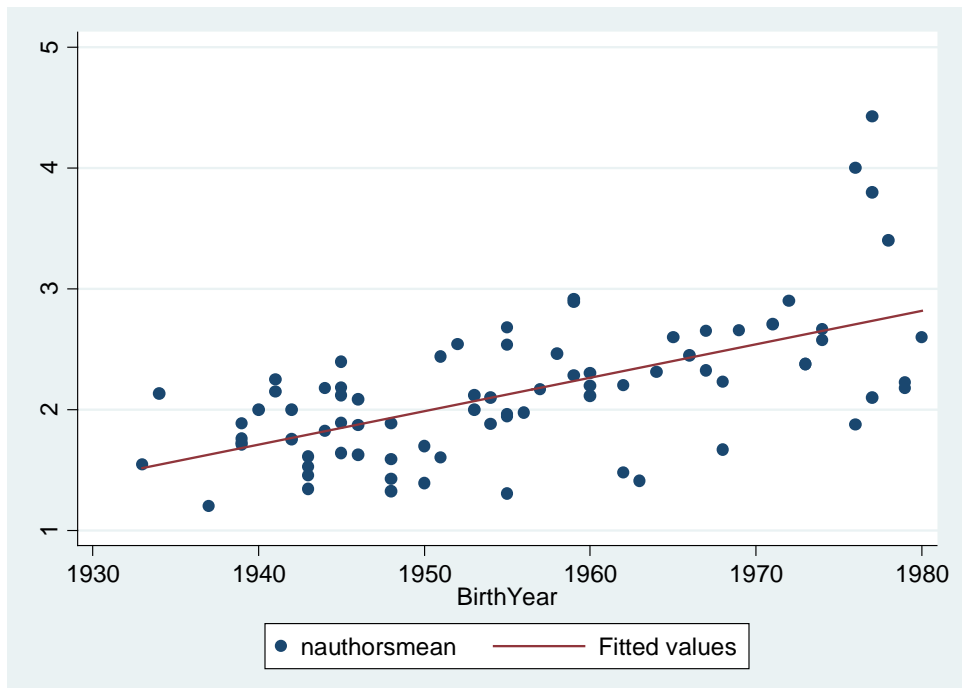

NAuthors $=-51.82+0.0277$ BirthYear, Adj. $\mathrm{R}^{2}=0.362$ (0.0041)

Figure 1b. Relation between Birth Year and Average Number of Authors, N = 79 


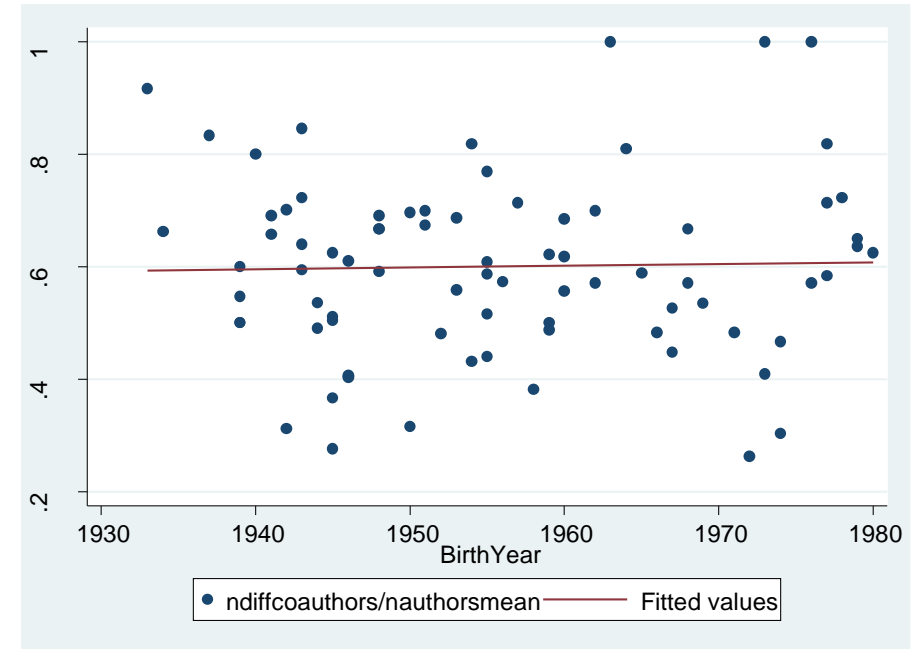

DifferentCoauthors/TotalCoauthors $=0.016+0.0003$ BirthYear, Adj. $\mathrm{R}^{2}=-0.012$ (0.0014)

Figure 2. Novelty of Coauthors by Birth Year of Author, $N=79$ 


\section{Appendix Table 1. Authors in the Labor Economists Sample}

\begin{tabular}{|c|c|c|}
\hline Abowd, J & Katz, L & Welch, F \\
\hline Abeler, J & Kennan, J & Wibral, M \\
\hline Abraham, K & Krueger, A & Willis, R \\
\hline Acemoglu, D & Kube, S & \\
\hline Altmann, S & Lang, K & \\
\hline Altonji, J & Lange, F & \\
\hline Angrist, J & Layard, R & \\
\hline Ashenfelter, O & Lazear, E & \\
\hline Autor, D & Lemieux, T & \\
\hline Bailey, M & Lundberg, S & \\
\hline Bandiera, O & MacLeod, W.B & \\
\hline Barankay, I & Mas, A & \\
\hline Bertrand, M & Meghir, C & \\
\hline Blank, R & Michael, R & \\
\hline Blau, F & Miller, A & \\
\hline Blundell, R & Moffitt, R & \\
\hline Borjas, G & Moretti, E & \\
\hline Brown, C & Mortensen, D & \\
\hline Burdett, K & Murnane, R & \\
\hline Cain, G & Murphy, K.M & \\
\hline Card, D & Neal, D & \\
\hline Carrell, S & Neumark, D & \\
\hline Chetty, R & Nickell, S & \\
\hline Chiappori, P-A & Pencavel, J & \\
\hline Chiswick, B & Pissarides, C & \\
\hline Currie, J & Pollak, R & \\
\hline Ehrenberg, R & Prendergast, C & \\
\hline Farber, H & Rasul, I & \\
\hline Freeman, R & Rosenzweig, M & \\
\hline Goldin, C & Shaw, K & \\
\hline Gronau, R & Shimer, R & \\
\hline Hall, R & Smith, James & \\
\hline Haltiwanger, J & Solon, G & \\
\hline Hamermesh, D & Stafford, F & \\
\hline Heckman, J & Taber, C & \\
\hline Hershbein, B & Todd, P & \\
\hline Hoekstra, M & Van Reenen, J & \\
\hline Kahn, L & Weiss, Y & \\
\hline
\end{tabular}

